\title{
New scientific approaches to evaluating accessibility of routes for disabled persons
}

\author{
Dmitriy Enin ${ }^{1,2 *}$ [0000-0002-9342-515X] \\ ${ }^{1}$ Moscow Automobile and Road Construction State Technical University (MADI), 125319, \\ Leningradsky prospect, Moscow, Russia \\ ${ }^{2}$ LLC «Institute of Applied Transportation Research» (IATR), 125080, Volokolamskoe highway, \\ Moscow, Russia
}

\begin{abstract}
The article presents the results of the study of the concept of «accessibility». It is shown that the term is used as a property and a figure of speech. In the form of a figure of speech, the concept contains the accessibility property, as well as properties and factors that affect the level of accessibility. Methodological approaches and results of field studies confirming the possibility of evaluating and describing the accessibility in terms of numeric expressions are presented. Field experiments were carried out in Rostov-on-Don and Novosibirsk with the participation of more than 90 respondents. Formalized mathematical definition of route accessibility for disabled is given as well as examples of defining the values of accessibility for certain categories of disabled people. Justification of feasibility of describing the accessibility of routes by means of level scale which excludes the drawbacks of binary system of accessibility evaluation is given. The incorrect usage of object-oriented approach for evaluating accessibility for disabled at different territories and transport systems is confirmed.
\end{abstract}

Keywords: accessibility, disabled people, method, route, scientific approach, transport, urban.

\section{Introduction}

In the course of the past decade, the issue of ensuring the accessibility for disabled people in terms of urban territories and transport in Russia has been given a boost. The need of planning and managing in this area has demanded the development of methods to define the accessibility and evaluate the level of it.

In valid regulations [1-3] the definition of accessibility level is made based on absolute and relative factors which indicate the numerical characteristics of the object and services accessible for disabled. Such approach has been defined as object-oriented [4-6].

The existing approach is convenient in terms of using the factors which are simple to identify and suitable for the state accounting policy. However, it has one major drawback: this approach doesn 't consider the character of interaction between the disabled people and the environment nor the directions and specific features of their routes. The capability and frequency of visiting the objects by the disabled people depends not only on the accessibility level of the facilities but also on the environment and transport accessibility. 
For those who are not able to go outside their houses or reach the service facility, the facility objects are inaccessible (previously, the fraction of such disabled people reached 35 $\%$ [4]). In the Convention on the Rights of Persons with Disabilities the route and transport accessibility are considered together with the accessibility of other facilities (accommodation houses, schools, medical facilities etc.) [7].

Therefore, new approach towards evaluating the accessibility for disabled people's routes is needed which will provide possible base to evaluate the accessibility of different level facilities and its transport systems.

\section{Problem statement}

The early studies accomplished by the author on demand of Russia Ministry of Transportation in 2013 [8] and 2015 concerning different regions of the country have proven the presence of numerical difference in the evaluation of accessibility of urban environment and transport system by the disabled people. However, these studies didn't include the evaluation of accessibility of certain itineraries of disabled, i.e. were confined to a general evaluation of accessibility of transport means.

In 2017, the hypothesis of differences between the results of the assessment of accessibility of objects and the route accessibility for the disabled was tested (the facilities were concerned as part of the routes). There was also necessity to evaluate how the obtained results affect the general accessibility evaluation of urban transport systems.

Simplified approach was used. It combined poll method with field research regarding the common routes for disabled people of two categories - blind and wheelchair persons. The results of study have proven the access level for transport infrastructure facilities about $40 \%$, transport means about $25 \%$, while the route accessibility level for the same facilities was as low as $4 \%$ [4]. Considering the consistency between the principles and communality of methodological approaches of accessibility evaluation, the difference between the results of the two approaches was as large as 28 . Therefore, an evident proof of hypothesis of discrepancy between the results of object-oriented and route-oriented approaches towards defining urban facilities and transport system accessibility has been obtained.

Object-oriented approach shouldn't be used for evaluation of the facilities and transport system accessibility for disabled people. However, because of using the simplified study methodology, there was a need to develop more substantive methodology ground as well as procedures to confirm the obtained results. At the same time two issues demanding additional studies have drawn attention:

- Low level of route accessibility has proven contradiction to the observations that the majority of the disabled people from the studied categories were able to move in the urban environment, either individually or with an accompanying person, which, most probably, was due to certain flaws of the accessibility evaluation methodology;

- There was no exact definition of «accessibility» while defining the accessibility of facilities and routes for disabled, which could cause misinterpretation of the obtained results due to different interpretation of the term by the respondents of study.

In 2020, within the framework of study requested by Russia Ministry of Transportation, evaluating the consistency of the earlier obtained observations was made possible along with making an effort to sort out the differences and form theoretical approaches in order to evaluate the route accessibility level for disabled.

The following issues have been emphasized in the study:

1) What is «accessibility» for the disabled?

2) Can the accessibility be evaluated and presented in terms of figures?

3) Can the accessibility have levels not bounded to the binary evaluation system? 
4) Is it possible to present mathematical description of the accessibility concerning routed of disabled?

\section{Methods}

The first issue was solved by means of documentary and analytical research methods of investigation.

The rest of the issues were solved using the following methodology:

1) Defining general methodical part of the study;

2) Formingthe list of criteria required for evaluating accessibility level of urban environment and transport elements (three groups of criteria were used: a) technical, the values of which are determined by instrumental methods (109 criteria); b) criteria of the respondents' score (6 criteria); c) criteria of the experts score (6 criteria));

3 ) Forming the list of evaluation means needed to define the values of accessibility criteria (i.e. GPS dashcam, digital spirit level, measure tape, optical heart rate monitor);

4) Defining target categories of disabled people for study (5 categories with total of 90 people were chosen: blind and partially sighted -3 subcategories; deaf; MSDs - 3 subcategories; people with cerebral palsy (CP);

5) Specifying planned routes for the chosen target groups of disabled peopled based on surveillance study (two planned routes were chosen - pedestrian and transport-pedestrian);

6) Conducting the pilot survey of the planned routes with the representatives of each category of disabled people in order to verify and specify the study methodology, developing project schedule of the study;

7) Selecting, guiding, surveying the respondents, guiding the accompanying persons (list of surveyed persons representing the target groups was defined by means of nonrandom sample; inside the target groups selecting the respondents was accomplished mainly in random manner);

8) Conducting an active experiment of respondents' assessment of the accessibility of planned routes and their elements;

9) Instrumental investigation of urban environment and transport elements along the established routes by means of direct valuation method;

10) Processing and analyzing study results.

The study was accomplished in two cities: Rostov-on-Don (main study - 70 respondents) and Novosibirsk (additional comparative study - 20 respondents). Fig. 1 shows video footage of the process of monitoring the movement of disabled people along routes and overcoming elements of the route.

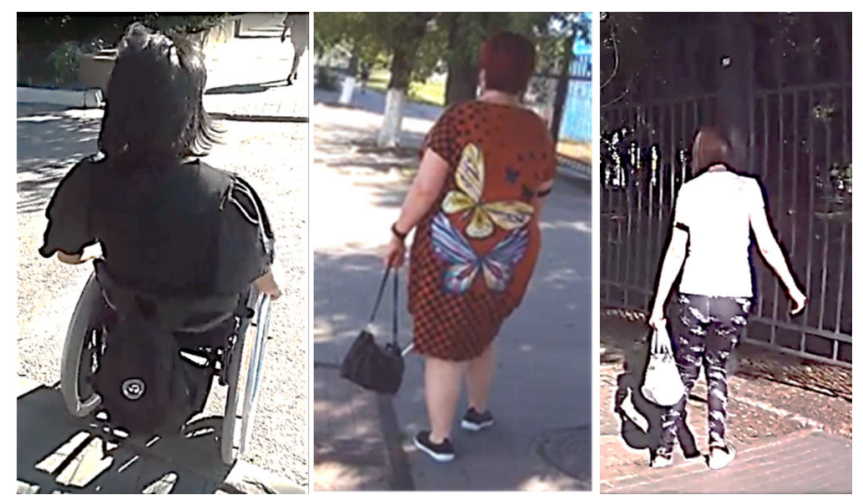

Fig. 1. Movement of disabled people along the route during the experiment. 


\section{Results}

1. Concerning the first issue, 19 sources were studied [9-12]. The analysis has shown that the accessibility (for disabled people) is general property of material and non-material objects, specified by being capable to be used by disabled people. Some authors find it necessary to specify this term with the words "with no difficulty» $[13,14]$. This term specifies different property - comfortability, as a quality characteristic of its level. Its meaning should be stated differently: «for all disabled people» (considering all the confinements of their body functions). For the sake of brevity of the definition, this note can be omitted. The study is described in detail in another article [15].

It should be noted that the concerned term has revealed at least two curious features:

- Accessibility supposes two aspects: an object with its characteristics and subject using this object with his/her own individual characteristics;

- The more complex an object is, the more accessibility depends on other characteristics and factors (e.g., danger of crossing multi-lane roadway with zebra crossing with intensive traffic experienced by the disabled person can present a serious psychologic barrier against using such crossing - characterizes the effect of safety properties and psychological characteristics of a certain person; other example: minor barriers encountered by the disabled person in wheelchair along a significant distance will confine his/her possibility to move, but on a short section, this will not lead to a refusal to move).

Thus, «accessibility» can be considered as a complex property. In Russian language there is no specific term yet; hence, it is being substituted with the term "accessibility» being only figure of speech. The same complex meaning of the concept is presented in Russian translation of the Convention on the Rights of Persons with Disabilities.

In certain cases, the concept is being described with terms «barrier-free» or «barrierless environment» [16-18]. «barrier-free» is closer by sense to the essence of the expected complex concept, since being applicable to description of human physics and behavior psychology. Nevertheless, it should not be considered reasonable enough due to certain disadvantages: it refers to characteristic, but not the property of an object; its essence is restricted by semantics of the term «barrier», «restraint»; it characterizes an object by means of its negative form and thus cannot be recognized as correct determination.

Next, «accessibility» will be considered as a complex concept. It includes the accessibility property and related properties and factors that affect its characteristics.

Accessibility in the study is considered regarding all disabled people, but not taking into account those in need of surgical treatment or other specialized aid or procedures outside the daily living activity of a person.

2. The answers to the second, third and fourth questions were found to be interrelated.

It was proved possible to measure the values of accessibility of elements of disabled people's routes. In order to solve this task, we had to subsequently use several methodological approaches: instrumental measurements of route elements' characteristics; scoring of the elements' accessibility by disabled people from target groups; statistical processing of received values with developing convenient normalized scale. Additionally, expert evaluation was made by the behavioral specialists (specializing in behavior of disabled people) in terms of interacting with route elements in order to calibrate the results obtained.

Procedures of investigation were found to be close to the normalizing procedures. The study, however, didn't include the setting of statistically valid sample amount, nor the definition of errors and acceptable variation of the values obtained. Such study can be performed in the long run.

According to the respondents ' estimates, uncalibrated values of the accessibility of the route elements were obtained (Fig. 2). Evaluation is performed using 6-point evaluation 
system ( 0 to 6 , where 0 - inaccessible, 1-2 - accessible with accompanying person only, 35 - accessible unassisted). The less values are, the more complex is the route; greater values indicate less difficulties for access. Intervals 1-2 and 3-5 were set to verify the possible presence of different accessibility levels.

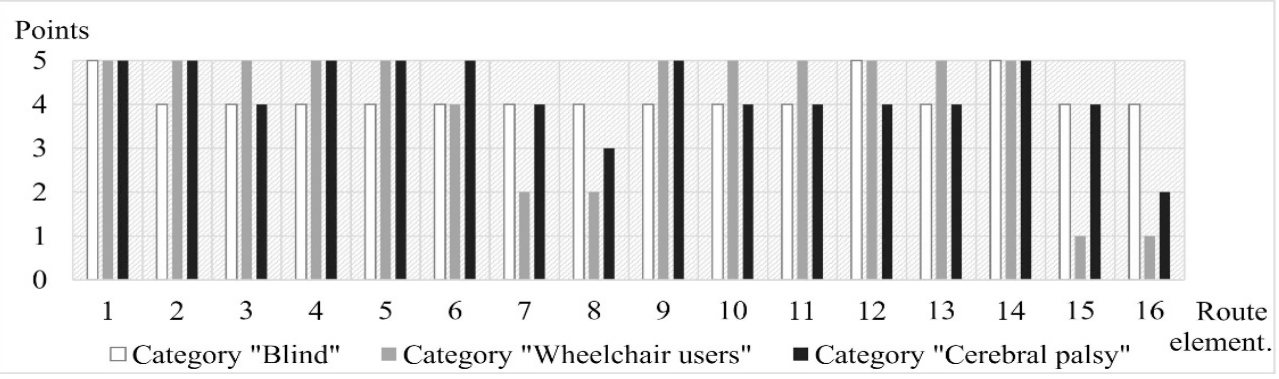

Fig. 2. Values of accessibility of route elements for three categories of disabled people. 1 - billboard support on the way $0,6 \mathrm{~m}$ wide; 2 - curb ramp on sidewalk with inclination of $47 \% \mathrm{~m} 2 \mathrm{~m}$ wide; $3-6$ limbs of the trees overhanging above part of a sidewalk (1,4 to $1,6 \mathrm{~m}$ above the ground); 7-8 - start and end of roadway crossing with no curb ramps (border stone level 15 and $9 \mathrm{~cm}$ ); 9 - sidewalk inclination $19 \%$; 10-11 - start and end of roadway crossing with no curb ramps (border stone level 6,5 и $7 \mathrm{~cm}$ ); 12 - passway crossing with no curb ramps (border stone level 5,5 and $6 \mathrm{~cm}$ ); 13 - curb ramp on sidewalk with inclination $64 \% 2$ m wide; 14 - undesignated row of bollards on the left side of the sidewalk; 15-16 - passway crossing with no curb ramps (border stone level $15 \mathrm{~cm}$ ).

Of several possible ways to define accessibility level of route elements, the most convenient for the first stage was found to be a formalized approach that allows to calculate values of accessibility coefficients for each element using the equation:

$$
K_{A}=1-\frac{1}{n} \sum_{i=1}^{n} \frac{1}{e^{1,1 x_{i}}},
$$

where $n$ - sample amount (number of respondents of a certain category that evaluated accessibility of an element), $x_{i}$ - value of $i$ element evaluation.

Selection of such statistics is justified by the need to obtain more considerable weight for the values with lesser score (such areas are more «sensitive» for disabled people), compared to high values. Such approach wasn't applicable to the standard evaluation method - evaluation of sample average and dispersion.

Table 1. Values of accessibility coefficient for route elements.

\begin{tabular}{|c|c|c|c|c|c|c|c|c|c|c|c|c|c|c|c|c|}
\hline \multirow{2}{*}{$\begin{array}{c}\text { Cate- } \\
\text { gory of } \\
\text { disabled }\end{array}$} & \multicolumn{16}{|c|}{ Route elements } \\
\hline & 1 & 2 & 3 & 4 & 5 & 6 & 7 & 8 & 9 & 10 & 11 & 12 & 13 & 14 & 15 & 16 \\
\hline Blind & $\stackrel{n}{\hat{\sigma}}$ & $\begin{array}{l}\infty \\
\infty \\
0 \\
0\end{array}$ & $\begin{array}{l}n \\
\infty \\
0 \\
0\end{array}$ & 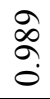 & $\begin{array}{l}0 \\
\infty \\
0 \\
0\end{array}$ & $\begin{array}{l}\hat{\infty} \\
\hat{0} \\
0\end{array}$ & $\begin{array}{l}\mathfrak{m} \\
\infty \\
0 \\
0\end{array}$ & $\begin{array}{l}1 \\
\infty \\
0 \\
0\end{array}$ & $\begin{array}{l}\infty \\
\hat{0} \\
0\end{array}$ & $\begin{array}{l}\hat{\infty} \\
0 \\
0\end{array}$ & $\hat{\infty}$ & बे & $\hat{\infty}$ & $\begin{array}{l}n \\
\infty \\
o \\
0\end{array}$ & $\hat{\infty}$ & $\begin{array}{l}0 \\
\infty \\
0 \\
0\end{array}$ \\
\hline $\begin{array}{l}\text { Wheel- } \\
\text { chair } \\
\text { users }\end{array}$ & $\begin{array}{l}\text { హे } \\
\text { ò }\end{array}$ & $\vec{\sigma}$ & مू & ふু & $\begin{array}{l}\circ \\
\text { ڤ̆ }\end{array}$ & $\begin{array}{l}\infty \\
\stackrel{\infty}{a} \\
0\end{array}$ & $\begin{array}{l}\stackrel{0}{0} \\
0\end{array}$ & $\frac{8}{\circ}$ & హু & مे & مू & مू & ڤ̆ & مे & $\underset{\tilde{\sigma}}{\tilde{\sigma}}$ & So \\
\hline $\begin{array}{c}\text { Cerebral } \\
\text { palsy }\end{array}$ & $\begin{array}{l}\circ \\
\text { ळ̆ } \\
\vdots\end{array}$ & $\begin{array}{l}\circ \\
\text { ळ̆ }\end{array}$ & $\begin{array}{l}\bar{\infty} \\
\stackrel{0}{0}\end{array}$ & 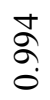 & 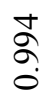 & $\stackrel{+}{\circ}$ & $\stackrel{\infty}{a}$ & $\begin{array}{l}\bar{b} \\
\infty \\
0\end{array}$ & $\begin{array}{l}\circ \\
\text { } \\
\text { ’ }\end{array}$ & $\begin{array}{l}\infty \\
\infty \\
0\end{array}$ & $\begin{array}{l}\infty \\
\infty \\
0\end{array}$ & $\underset{\infty}{\infty}$ & $\begin{array}{l}\bar{\infty} \\
0\end{array}$ & 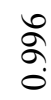 & $\frac{\mathrm{N}}{\sigma}$ & $\frac{\mathfrak{r}}{\dot{I}}$ \\
\hline
\end{tabular}

An example of the results of calculation of route elements' accessibility coefficient made by the equation (1) considering the values is presented in Table 1. In this case and for the 
following evaluations, values obtained from each respondent are used instead of the average values shown in Fig. 2.

Route accessibility value for disabled can be obtained by the equation:

$$
K_{A r_{j}}=1-\sum_{f=1}^{K} \sum_{i=1}^{k}\left(1-K_{A_{f i}}\right),
$$

where $K_{A f i}$-accessibility coefficient for i route element, units; $k$ - total number of elements encountered on the route, units; $K$ - total number of route parts (pedestrian, ride on one means of transport, transfer, ride on other means of transport, pedestrian etc., defined by the route complexity), units.

Final values of route accessibility for the three exampled categories of disabled people are shown in the Fig. 3.

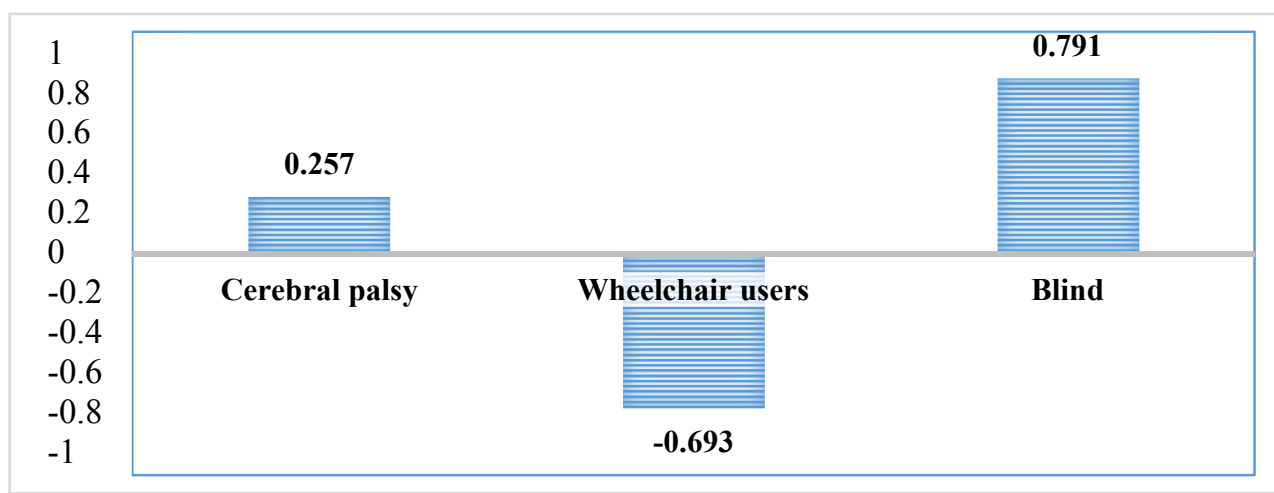

Fig. 3. Route accessibility values for three categories of disabled.

Negative value seen at the picture shows high rate of route inaccessibility caused by several impassable barriers for several respondents at the same time at areas 7,8 and 15, 16. This specifies the evaluation of route accessibility coefficient, i.e. using «sensitive» «accumulative effect». It means that in certain conditions, a number of frequently encountered route elements with middle or relatively high accessibility level at some point becomes comparable with the accessibility level of a single element with low accessibility level in terms of its overall importance. Therefore, complex of route elements that are hard to pass or unpassable for at least several respondents from the same target group shall overbalance the evaluations of other respondents and may as well lead to obtaining negative values (values equal or less than zero characterize the routes as inaccessible). Such logic of reasoning and its formalized presentation best reflect the property of accessibility that was adopted in clause 1 .

To make a final decision regarding route accessibility level for different categories of disabled people, limit values of accessibility coefficient have been defined using experimental approach (Table 2).

Table 2. Values of accessibility coefficient for route elements.

\begin{tabular}{|c|c|c|}
\hline Level & Range of values of route accessibility coefficient & Route characteristics \\
\hline 5 & Over 0.9 & Doesn`t present difficulties \\
\hline 4 & $(0.7 ; 0.9)$ & Minor difficulties \\
\hline 3 & $(0.5 ; 0.7)$ & Major difficulties \\
\hline 2 & $(0 ; 0.5)$ & Critical difficulties \\
\hline 1 & Less or equal 0 & Inaccessible \\
\hline
\end{tabular}


Based on the table above, it can be concluded that for blind disabled persons the investigated route causes minor difficulties while for wheel chaired persons this route is inaccessible; it causes critical difficulties for disabled persons with cerebral palsy.

The presented example can additionally solve the third question in detail. In case of using the binary system of evaluation for disabled people with cerebral palsy and blind people the route is claimed accessible (since there is no «inaccessible» evaluation); as for the wheelchaired people, it is inaccessible.

Such model, however, doesn 't allow to characterize the route for disabled people based on the definition of «accessibility» from the management point of view. If the route is accessible for disabled people with cerebral palsy, no solution is needed. Nevertheless, route characteristics drawn from the Table 2 state the contrary: for this group of disabled people moving along the route shall cause critical difficulties that require activities towards improving characteristics of elements which compose the route. Anticipating the suggestion of feasibility to reshape the evaluation scale, we should note the incorrectness of such suggestion due to the discrepancy with the agreed definition of term «accessibility»: the route which can be passed, even with difficulty, will be accessible anyway. Therefore, levels of accessibility reflect the rate of impact of accompanying properties and factors and allow to characterize the state of accessibility more precisely.

The obtained results solve the answers to the three questions set in the study:

1) The possibility of measuring and numerically estimating the accessibility of routes for the disabled on the basis of the proposed methodological approaches is confirmed;

2) Presentation of accessibility characteristics as multi-level evaluation scale has been proven possible and feasibility has been justified.

3) The possibility of mathematical description of disabled peoples' route accessibility has been confirmed; examples of such description have been presented.

3. In course of study, unexpected follow-up result has been obtained. It has been found that the suggested approach towards defining the accessibility of routes of disabled people, on condition of certain enhancements (not presented in this study) is suitable for the complex evaluation of accessibility of facilities of any area along with its transport systems. The flow chart of problem solution model (Fig. 4) developed as a base gives a clear representation of placing the object- and route-oriented approaches.

An example of a possible implementation of the proposed approach is shown in Fig. 5. The accessibility of routes between the entrances of residential buildings and the bus stop is determined using the walking time criteria.

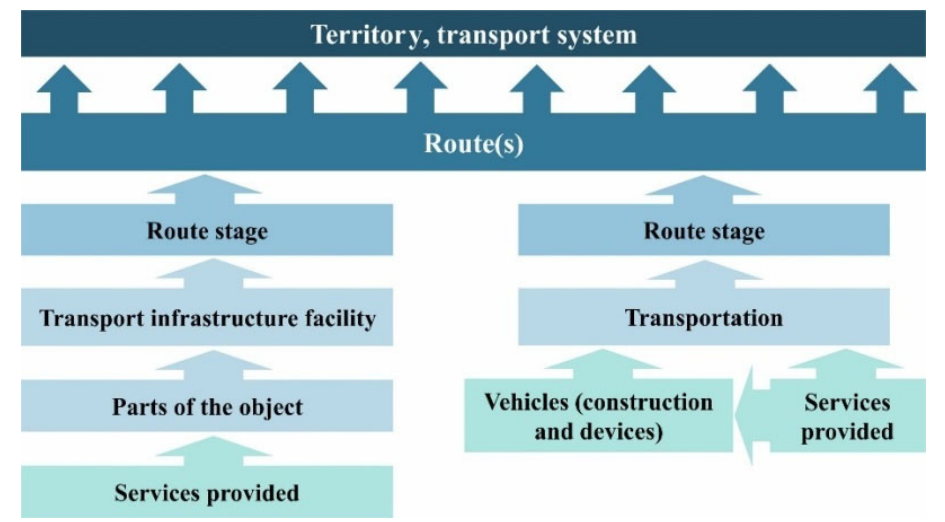

Fig. 4. Flow chart for the model of evaluating facility and transports system accessibility level for disabled people. 


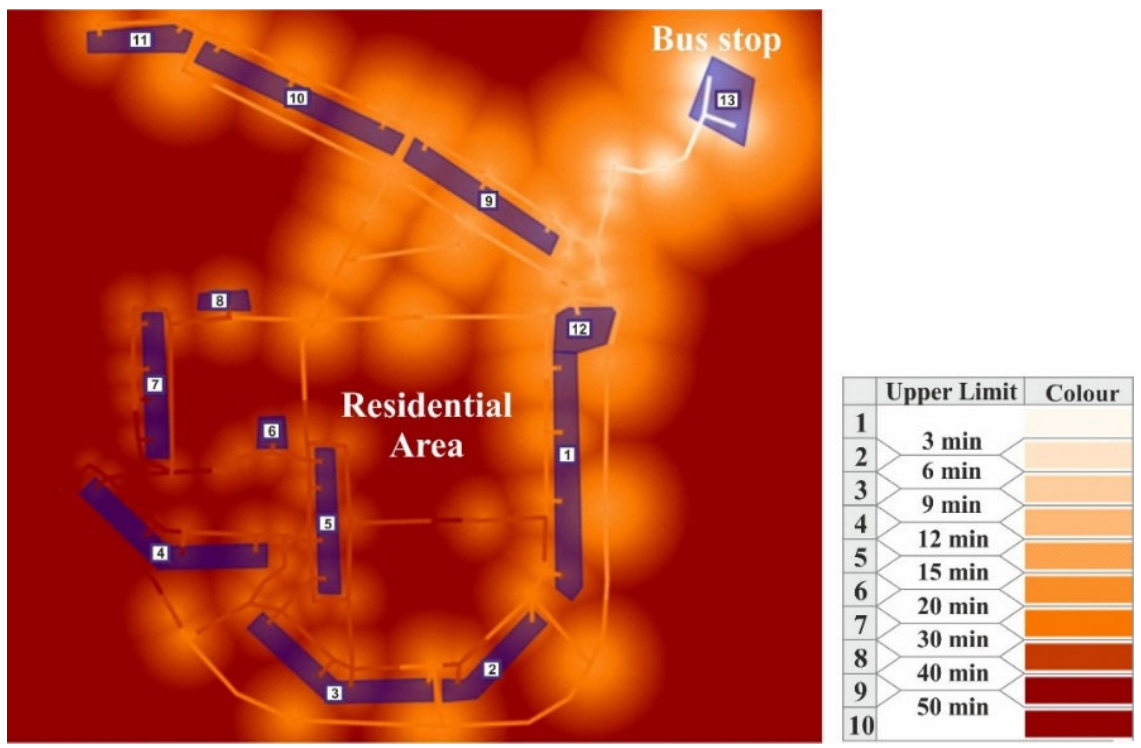

Fig. 5. Heatmap of the availability of routes to the bus stop.

\section{Conclusions}

The term «accessibility» should be considered more broadly than its eponymous property. Other properties and external factors that affect the accessibility of routes should also be considered. The possibility of formalization and calculation of accessibility of routes for the disabled is proved. This allows you to abandon the subjective methods of determining accessibility. The proposed calculation methods are applicable for planning, assessing compliance and monitoring accessibility of routes for the disabled. It is proved for the first time that the accessibility of the territories of cities and their transport systems can be determined on the basis of a route-oriented approach. It is based on the assessment of the availability of a set of possible routes. The results obtained are the basis for theoretical and practical developments on accessibility in urban planning and transport.

\section{References}

1. The State program «Accessible Environment for 2011-2025», Decree of the Government of the Russian Federation of 29.03.2019 No. 363, Russia (2019)

2. Transport Strategy of the Russian Federation for the period up to 2030, Order of the Government of the Russian Federation of 22.11.2008 No. 1734-r, Russia (2019)

3. On Approval of the Procedure for Ensuring Accessibility for Disabled Passengers of Motor Vehicles and Urban Ground Electric Transport, Bus Stations, Bus Stations and Services Provided, as well as providing them with the necessary assistance, Order of the Ministry of Transport of the Russian Federation of 01.12.2015 No. 347, Russia (2015)

4. A. E. Lysenko, I. A. Gunderov, D. V. Enin, O. D. Samarina, Monitoring and public control of accessibility for disabled people of urban environment objects on the basis of a route-oriented model: Methodological recommendations, National Center for Disability Problems, Moscow, Russia (2017)

5. Z. S. Lancaster, R. B. Binder, K. Matsui, P. Yang, Developing a theory of an objectoriented city: Building energy for urban problems, Energy Procedia, 158, 4210-4217 (2019) DOI: 10.1016/j.egy-pro.2019.01.807 
6. L. O. Marquez, S. Maheepala, An object-oriented approach to the integrated planning of urban development and utility services, Computers Environment and Urban Systems, 20 (4), 303-312 (1996) DOI: 10.1016 / S0198-9715 (96) 00023-3

7. Convention on the Rights of Persons with Disabilities (2006)

8. D. V. Enin, Research of accessibility of the transport system of Russia for low-mobility groups of the population, The Science. Technic. Management, 11, 68-74 (2013)

9. World Programme of Action Concerning Disabled Persons, UNGA 57, A/RES/37/52 (1982)

10. S. I. Ozhegov, Explanatory dictionary of the Russian language (Moscow, Russia, 2020)

11. V. Dal, Explanatory dictionary of the living Great Russian language (Saint Petersburg, Russia, LXXXIV,494-495, 1880)

12. Two accessibility, or why accessibility and availability are not the same, URL: habr.com/ru/post/301172 (last accessed: 25.04.2021)

13. J. Ryan, R. H. M. Pereira, What are we missing when we measure accessibility? Comparing calculated and self-reported accounts among older people, Journal of Transport Geography, 93 (2021) DOI: 10.1016/j.jtrangeo.2021.103086

14. E. Grisé, G. Boisjoly, M. Maguire, A. El-Geneidy, Elevating access: Comparing accessibility to jobs by public transport for individuals with and without a physical disability, Transportation Research Part A: Policy and Practice, 125, 280-293 (2019) DOI: $10.1016 /$ j.tra.2018.02.017

15. D. V. Enin, Research of the concept of "accessibility» in the context of the observance of the rights of disabled people, Transport of the Russian Federation, 88-89, 14-18, Russia (2020)

16. C. Wu, L. Juan, L. Xi, Using community planning method to improve effect of urban barrier-free transportation system, Transportation Research Procedia, 25, 4330-4337 (2017) DOI: 10.1016/j.trpro.2017.05.29

17. N. E. Ayse, Raising Awareness about Accessibility, Procedia - Social and Behavioral Sciences, 47, 490-494 (2012) DOI: 10.1016/j.sbspro.2012.06.686

18. Barrier-Free Concept' Instructions - Accessible Public Buildings, Senate Department for Urban Development and Housing, Berlin (2018) 